\title{
Elevation of feed intake in parasite-infected lambs by central administration of a cholecystokinin receptor antagonist
}

\author{
Robyn A. Dynes*†, Dennis P. Poppi $\ddagger$, Graham K. Barrell and Andrew R. Sykes \\ Animal and Veterinary Sciences Group, PO Box 84, Lincoln University, Canterbury, New Zealand
}

(Received 9 December 1996 - Revised 14 April 1997 - Accepted 11 June 1997)

\begin{abstract}
The role of cholecystokinin (CCK) in modulating feed intake depression in parasite-infected lambs was investigated using CCK receptor antagonists (L364-718 and loxiglumide). Four experiments were carried out using ewe lambs infected with 4000 Trichostrongylus colubriformis larvae/d or non-infected controls $(n 8$, live weight $25 \mathrm{~kg}$ ). Animals were fed daily on a nutritionally complete pelleted diet and had free access to water. In the first experiment, infected and non-infected animals were injected subcutaneously with CCK

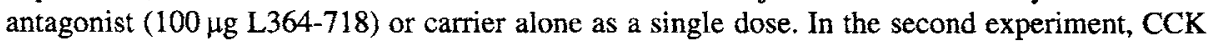
antagonist (loxiglumide: $0,5,10$ or $20 \mathrm{mg} / \mathrm{kg}$ live weight) was injected into a jugular vein immediately before feeding. In the third experiment, animals were infused continuously with the CCK antagonist (loxiglumide; $10 \mathrm{mg} / \mathrm{kg}$ per h) for $10 \mathrm{~min}$ before feeding and for the first $2 \mathrm{~h}$ of feeding. In the final experiment, lambs were fitted with an indwelling cerebral ventricular cannula and infused with a CCK antagonist (loxiglumide, $162 \mu \mathrm{g} / \mathrm{min}$ ), CCK agonist (CCK-8, $2.5 \mathrm{pmol} / \mathrm{min}$ ), loxiglumide plus CCK-8 or sterile saline solution alone via the cannula for $30 \mathrm{~min}$ before feeding and for the first $60 \mathrm{~min}$ of feeding. In all the experiments short-term feed intake was recorded at 10 and $15 \mathrm{~min}$ intervals for the first and second hours of feeding respectively, then at hourly intervals for the remainder of the $8 \mathrm{~h}$ recording period. Peripheral injection with L364-718 or loxiglumide did not elevate feed intake in either the infected or noninfected animals. However, feed intake was increased $(P<0.05)$ in the short term by central infusion of loxiglumide, this effect being greater in the infected animals and apparently due to an elevation in intake during the second hour of feeding. CCK-8 depressed short term feed intake only in the infected animals $(P<0.05)$. Total daily feed consumption was not influenced by any of the pharmacological agents. The results indicate an involvement of central CCK receptors in regulation of feed intake depression following gastrointestinal parasitism of sheep and the possibility of a similar role in non-infected sheep. They do not support the singular importance of a peripheral action of CCK in determining satiety.
\end{abstract}

Cholecystokinin: Loxiglumide: Feed intake: Gastrointestinal parasites

Gastrointestinal parasite infection in growing lambs can lead to significant production losses, attributable to a reduction in the efficiency of use of metabolizable energy and a reduction in voluntary feed intake (Poppi et al. 1990). Although a reduction in voluntary feed intake is commonly reported, little is known of the mechanisms of this depression.

In the regulation of 'normal' intake it is highly improbable that a single pathway would regulate intake but the temporary/reversible nature of parasite induced intake depression suggests that a single pathway may cause the intake depression in this instance. Gastrointestinal hormones may be involved in such pathways and one of these, cholecystokinin (CCK), has been linked to intake depression in infected lambs (Symons \& Hennessey, 1981). The action of CCK in causing such intake depression may involve any of at least three mechanisms. First, peripheral CCK stimulation of the brain via vagal afferents may have

Abbreviations: CCK, cholecystokinin; $\mathrm{W}^{0.75}$, metabolic body weight.

* Corresponding author: Dr R. A. Dynes, fax +61 89387 8991, email r.dynes@ccmar.csiro.au

$\dagger$ Present address: CSIRO, Private Mail Bag, P.O. Wembley, WA 6014, Australia.

$\ddagger$ Present address: Department of Agriculture, University of Queensland, St Lucia, 4072, Australia. 
a direct satiety effect (Hoebel, 1985). Second, release of CCK from sites along the gastrointestinal tract may alter the rate of gut emptying and therefore indirectly reduce intake. Finally, CCK from peripheral circulation may be secreted into cerebrospinal fluid and be transported to receptive sites within the brain. The possible role of CCK in the feed intake depression and changes to intestinal motility which accompany gastrointestinal worm infection have not been investigated beyond the original studies of Symons \& Hennessy (1981). This line of investigation has been hindered by the lack of reliable assays to measure changes in circulating concentrations of CCK. An alternative experimental approach for studying the role of CCK lies with the use of its antagonists, such as loxiglumide (CR1505, Rotta Research Laboratorium, Monza, Italy) and L364-718 (Merck, Sharpe and Dohme, Harlow, Essex, UK). In vitro and in vivo studies (Chang \& Lotti, 1986; Setnikar et al. 1987b) have shown that both these compounds are potent, specific antagonists of CCK receptors, with high affinity for the CCK-A receptors which occur mainly in peripheral tissues.

Evidence exists for an involvement of CCK in central control of feed intake. For sheep Marson et al. (1986) have located specific CCK receptors in the hypothalamus and Morley et al. (1981) reported that fasting decreased CCK levels in this part of the brain of sheep. Injection of CCK into the cerebral ventricles of sheep reduced feed intake (Della-Fera \& Baile, 1979) and injection of a CCKantibody at the same site stimulated feeding (Della-Fera \& Baile, 1981). Our hypothesis is that CCK mediates the anorexia in sheep caused by gastrointestinal parasitism.

The present series of studies was designed to determine the role of $\mathrm{CCK}$ in parasite-infected sheep by examining the effects of CCK antagonists, administered systemically or centrally, on short-term feed intake and gut emptying. In particular we wished to determine whether intake depression could be overcome in the short term by blockade of CCK receptors.

\section{Materials and methods}

\section{Animals}

Four experiments used Coopworth $\times$ Dorset Down-cross ewe lambs, weaned at approximately $17 \mathrm{~kg}$ live weight and reared to minimize exposure to gastrointestinal parasites. When the average live weight was $25 \mathrm{~kg}$, sixteen animals were ranked on the basis of live weight and randomly allocated to a parasite-infected or non-infected group $(n 8)$. Infected animals received 4000 Trichostrongylus colubriformis larvae/d administered orally as bulked doses three times/week on filter paper, while non-infected animals received only moistened filter paper tablets.

\section{Feeding and measurement of feed intake}

A complete pelleted ration was offered ad libitum in all experiments. Diet composition was $(\mathrm{g} / \mathrm{kg})$ : cereal straw 300 , barley grain 490 , field peas 200 and trace elements 10 . Average proximate analysis was $(\mathrm{g} / \mathrm{kg})$ : crude protein 185 , fat 15 and neutral-detergent fibre 312 . Feed refusals were removed daily at 07.30 hours and all animals were deprived of food for $2 \mathrm{~h}$, to standardize the time of the first meal at 09.30 hours. Short term feed intake was recorded over $8 \mathrm{~h}$ by weighing feed remaining at 10 min intervals for the first hour, $15 \mathrm{~min}$ intervals for the second hour and hourly for the remainder of the $8 \mathrm{~h}$ measurement period. Daily feed intake (consumed over the $22 \mathrm{~h}$ period in which feed was available) was determined each day from feed offered minus refusals.

\section{Parasitology}

Faeces were taken manually from the rectum of each lamb on a weekly basis and processed immediately to determine faecal egg concentration by a modified McMaster method (Ministry of Agriculture, Fisheries and Food, 1979). Animals were weighed weekly at 08.00 hours before feeding except during treatment runs.

\section{Experimental design and procedures}

In each experiment administration of treatments commenced when daily feed intake was depressed by at least $20 \%$ in infected lambs. At the completion of the treatment period, all animals were orally dosed with anthelmintic ( $200 \mu \mathrm{g}$ ivermectin $/ \mathrm{kg}$ live weight, Ivomec, Merck, Sharp and Dohme) and short term and daily feed intake monitored during intake recovery. All procedures used in these studies were conducted with prior approval from the Lincoln University Ethics of Animal Experimentation Committee.

\section{Expt 1: single dose study (L364-718)}

The CCK antagonist L364-718 was administered to infected and non-infected lambs $(n 8)$ as a single dose using a replicated Latin square design. At $15 \mathrm{~min}$ before feeding lambs were injected subcutaneously with $100 \mu \mathrm{g}$ of the CCK antagonist (L364-718, Merck, Sharp and Dohme) which had been dissolved in $0.5 \mathrm{ml}$ dimethyl sulfoxide under sterile conditions.

\section{Expt 2: dose-response study (loxiglumide)}

A replicated duplicate Latin square design (eight infected animals paired with eight non-infected animals receiving two replicates of each of four treatments) was used to determine the dose-response relationship between loxiglumide and feed intake. Immediately before feeding animals were injected intravenously with $0,5,10$ or $20 \mathrm{mg}$ loxiglumide (Rotta Research Laboratorium) per $\mathrm{kg}$ live weight via a temporary indwelling catheter into a jugular vein $(16 \mathrm{G} \times 50 \mathrm{~mm}, 51 \mathrm{~mm} \times 1.3 \mathrm{~mm}$ i.d., Surflo i.v. catheter, Terumo Corporation, Tokyo, Japan). Loxiglumide was supplied in sterile glass vials containing $5.4 \mathrm{~g} / \mathrm{l}$ of sodium salt of loxiglumide in phosphate-buffered saline solution, the zero dose $(0 \mathrm{mg})$ consisting of phosphatebuffered saline solution only. Prepared solutions were drawn from sterile vials into $60 \mathrm{ml}$ syringes. Each syringe was attached directly onto the catheter and the solution infused steadily over $2-3 \mathrm{~min}$. 


\section{Expt 3: continuous infusion study (loxiglumide)}

The study of effects of continuous infusion of the CCK antagonist was run in two parts. At three weeks before the commencement of the experiment, all animals were surgically fitted with an abomasal cannula (Hecker, 1974).

Part 1. Following the onset of feed intake depression, infected and non-infected lambs ( $n$ 6) were infused with loxiglumide for $130 \mathrm{~min}$ via a temporary indwelling catheter (as for Expt 2) into a jugular vein. Loxiglumide powder was dissolved in sterile phosphate-buffered saline solution which had been adjusted to $\mathrm{pH} 7.6$ to increase solubility and the resulting $10 \mathrm{mg} / \mathrm{ml}$ solution was filtered through a bacterial filter $(0.2 \mu \mathrm{m}$ cellulose acetate filter, Advantec, Toyo Roshi Kaisha Ltd, Japan). The infusion was via gravity feed, using sterile tubing. Initially the solution was administered at a rate of $1 \mathrm{ml} / \mathrm{min}$ for $10 \mathrm{~min}$. The infusion rate was reduced to $0.3 \mathrm{ml} / \mathrm{min}$ (approximately $10 \mathrm{mg} / \mathrm{kg}$ per $\mathrm{h}$ ) for the remaining $2 \mathrm{~h}$, as recommended to maintain a steady state level of loxiglumide in circulation (L Rovati, Rotta Research Laboratorium, personal communication). Sheep were fed following the initial $10 \mathrm{~min}$ infusion and intake recorded as described earlier. The procedure was repeated using the saline solution alone on another day.

Part 2. In Part 2, the procedure was carried out as for Part 1 with the addition of a single dose of radioactive marker, the ${ }^{51} \mathrm{Cr}$ complex of EDTA $(10 \mathrm{ml}$ solution containing $6 \mathrm{MBq}{ }^{51} \mathrm{CrEDTA}$, Amersham Australia Pty Ltd, Australia). This was injected into the abomasum via the abomasal cannula $45 \mathrm{~min}$ after feeding, a time which corresponded to the end of the first eating period. Abomasal samples were then collected at $15,30,45,60,75,90,105$, 120 and $135 \mathrm{~min}$ following injection. Each sample was immediately mixed and a $10 \mathrm{ml}$ portion taken for determination of radioactivity using a gamma scintillation spectrometer (1282 Compugamma Universal Gamma Counter; LKB Wallac, Turku, Finland). The samples and standards were stored at $4^{\circ}$ until counted, within $4 \mathrm{~d}$ of collection. Calculation of abomasal volume, flow and retention time was carried out by marker analysis using regression analysis on the natural logarithms of the adjusted radioactivity counts (Faichney, 1975).

\section{Expt 4: continuous infusion into a lateral ventricle of the brain (CCK-8 and loxiglumide)}

Infected and non-infected lambs $(n 8)$ were fitted surgically with a stainless steel cannula $(20 \mathrm{~mm} \times 1 \mathrm{~mm}$ i.d. $)$ chronically implanted into a lateral cerebral ventricle (GSG Spencer, personal communication) 2 weeks after parasite dosing commenced. This ensured a minimum postoperative period of 3 weeks before the infusions were carried out.

Intracerebroventricular treatments 1-4 (following) were randomly allocated using a Latin square design and the solutions were infused at a rate of $0.03 \mathrm{ml} /$ minute for $90 \mathrm{~min}$; $30 \mathrm{~min}$ before feeding and for the first hour following feeding. Treatment 1: sterile phosphate-buffered saline solution, $\mathrm{pH} 7.0$ (control). Treatment 2: CCK-8 in sterile phosphate-buffered saline solution (CCK-8
$\left(\mathrm{Tyr}\left(\mathrm{SO}_{3} \mathrm{H}\right)^{27}\right)$, fragment 26-33, product no. 9271, Sigma Chemical Co. St Louis, MO, USA) infused at $2.5 \mathrm{pmol} / \mathrm{min}$ (CCK). Treatment 3: $5.4 \mathrm{~g} / 1(\mathrm{w} / \mathrm{v})$ of sodium salt loxiglumide $(162 \mu \mathrm{g}$ loxiglumide $/ \mathrm{min})$ in sterile phosphatebuffered saline solution (CCK antagonist). Treatment 4: CCK- 8 as in treatment 2 plus loxiglumide as in treatment 3 (CCK plus antagonist). Treatment solutions were drawn into sterile $3 \mathrm{ml}$ syringes connected to sterile tubing ( $1 \mathrm{~mm}$ i.d.) infusion lines and infused using a multichannel syringe pump. After 30 min of continuous infusion all animals were fed and intake recording commenced as described earlier. Infusion continued for the next $60 \mathrm{~min}$ so that a total of 90 min infusion occurred.

\section{Statistical methods}

Cumulative feed intake data did not meet the assumptions of normality, so a general linear model (GLM, SAS 6.1, Statistical Analysis Systems Institute, Cary, NC, USA) for unbalanced data was carried out on the ranked values (nonparametric analysis) and least square differences used to test differences between means. Rank values have no biological meaning, so data are presented as raw means. Means of abomasal volume, flow, retention time and the time taken for half the radioactive counts to leave the abomasum ( $t_{1 / 2}$ ) were tested using GLM and a Duncan's new multiple range test for differences between individual means.

\section{Results \\ Live weight}

Mean live weight increased in both infected and noninfected lambs in all experiments. Non-infected lambs gained more weight $(4.7,4.3,9.8$ and $2.2 \mathrm{~kg})$ than infected lambs in Expts 1-4 respectively. The increased weight gain was significant in Expts 2 and 3 but not in Expts 1 and 4 .

\section{Faecal egg counts}

Mean and peak production of $T$. colubriformis eggs in infected lambs was between 1000 and 2000 eggs/g faeces, except for Expt 3 where mean and peak egg output values were 5500 and $9000 / \mathrm{g}$ respectively.

\section{Daily feed intake}

The daily intake by non-infected animals was $90-140 \mathrm{~g}$ $\mathrm{DM} / \mathrm{kg}$ metabolic body weight $\left(\mathrm{W}^{0.75}\right)$ across all 4 experiments. Parasite-induced intake depression was usually significant 5-6 weeks after trickle dosing commenced (Fig. 1). The daily intake of infected animals during intake depression was $50-110 \mathrm{~g} \mathrm{DM} / \mathrm{kg} \mathrm{W}^{0.75}$. Intake depression in the infected animals ranged from 10 to $60 \%$ and treatments were imposed when intake depression was in the range $30-60 \%$ (Fig. 1). 


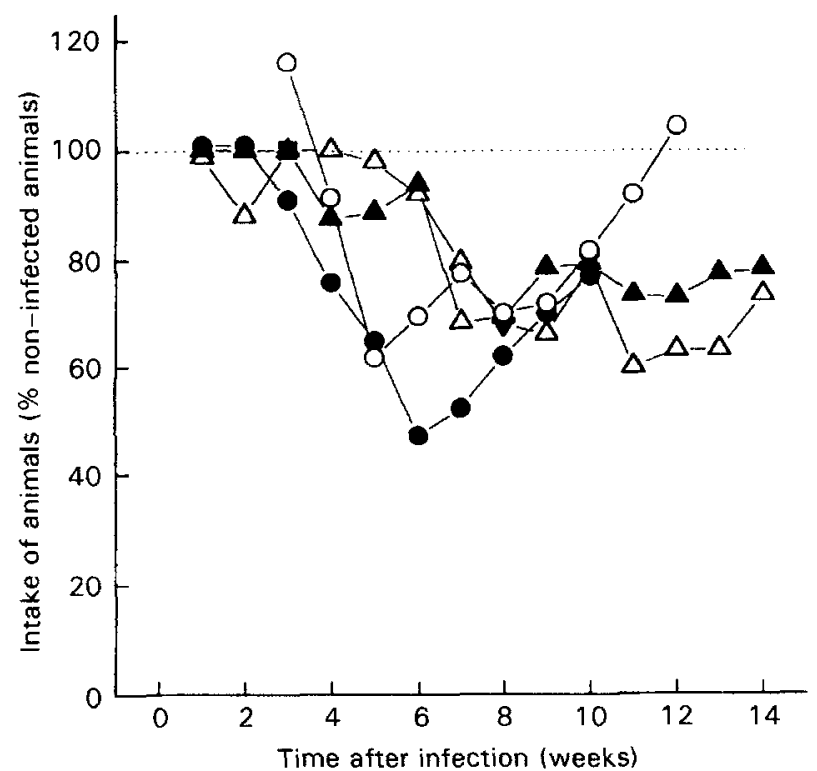

Fig. 1. Average daily feed intake of lambs infected with the parasite Trichostrongylus colubriformis as a percentage of the intake by their non-infected counterparts in four different experiments with cholecystokinin antagonists: $(O)$, single dose (Expt 1); $(\triangle)$, doseresponse (Expt 2); (@), continuous infusion (Expt 3) and (A), intracerebroventricular infusion (Expt 4). For details of procedures, see pp. 48-49.

\section{Short-term intake}

Short-term cumulative feed intake values for the infected lambs before, during intake depression and following intake recovery after anthelmintic treatments are shown in Fig. 2. Short-term cumulative feed intake was significantly lowered at all recorded time intervals during intake depression in infected animals (weeks 8-12). Following anthelmintic treatment and recovery of daily intake, short term feed intake returned to pre-infection levels.

\section{Effects of pharmacological agents}

Neither a single subcutaneous dose of L364-718 (results not presented) nor increasing doses of intravenous loxiglumide (Fig. 3) or continuous infusion of loxiglumide (Fig. 4) significantly increased short term feed intake in either infected or non-infected sheep at any recorded time period. Nevertheless, some trends were discernible. With increasing dose of loxiglumide there was a trend toward increased feed intake in the infected animals (Fig. 3) whereas non-infected animals tended to have reduced feed intake with increasing dose or infusion of loxiglumide (Figs. 3 and 4).

CCK-8 infused alone into a lateral ventricle of the brain for $30 \mathrm{~min}$ before feeding and for the first hour of feeding reduced feed intake of the infected animals in the first hour (Fig. 6). The resulting reduction in intake $(41-55 \%)$ was significant for $7 \mathrm{~h}$ after feeding $(0.05>P>0.001)$ (Fig. 6).

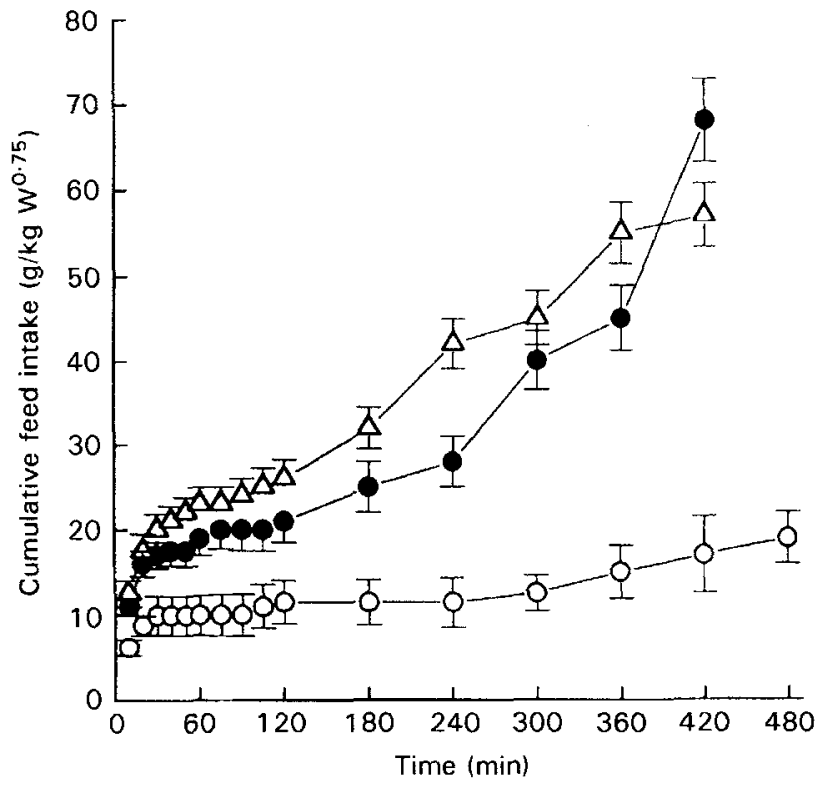

Fig. 2. Mean daily cumulative feed intake $\left(\mathrm{g} / \mathrm{kg}\right.$ body weight $\left.{ }^{0.75}\right)$ of lambs $(n 8)$ before infection with the parasite Trichostrongy/us colubriformis (O), during infection (O) or following anthelmintic treatment and full intake recovery $(\Delta)$. Standard errors of the mean values are represented by vertical bars.

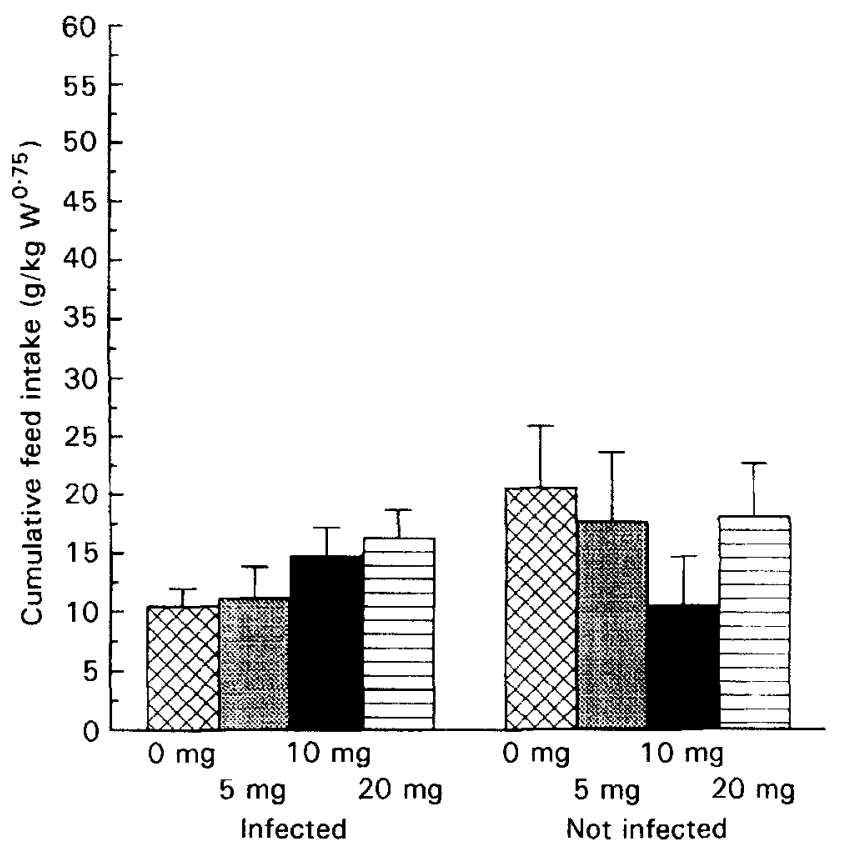

Fig. 3. Mean cumulative feed intake $\left(\mathrm{g} / \mathrm{kg}\right.$ body weight $\left.{ }^{0.75}\right)$ of lambs (n 8), infected or not infected with the parasite Trichostrongy/us colubriformis, $1 \mathrm{~h}$ after feeding following intravenous injection of 0,5 , 10 or $20 \mathrm{mg} / \mathrm{kg}$ live weight of the cholecystokinin antagonist, loxiglumide. Standard errors of the mean values are represented by vertical bars.

CCK-8 had no effect on the cumulative feed intake of noninfected animals (Fig. 5).

Loxiglumide elevated feed intake in both non-infected and infected groups when infused into a ventricle of the 


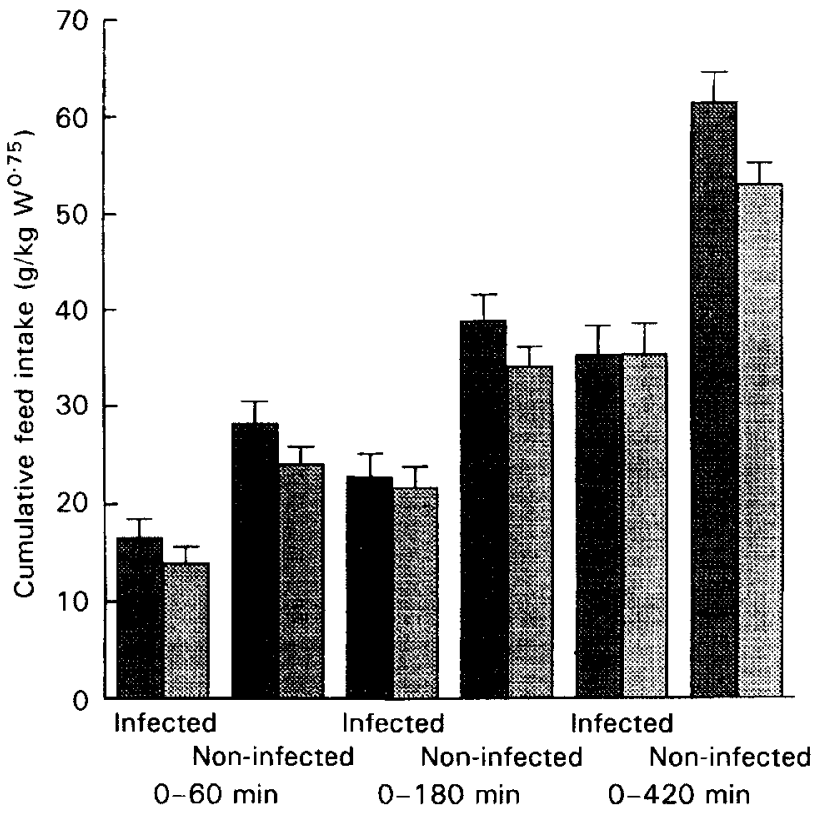

Fig. 4. Mean cumulative feed intake $\left(\mathrm{g} / \mathrm{kg}\right.$ body weight ${ }^{0.75}$ ) of lambs ( $n$ 8), infected or not infected with the parasite Trichostrongylus colubriformis, 60,180 and $420 \mathrm{~min}$ after feeding. Lambs were fed once daily and infused intravenously with saline solution ( $(1)$ or the cholecystokinin antagonist, loxiglumide (國) for $10 \mathrm{~min}$ before feeding and for the first $2 \mathrm{~h}$ of feeding. Standard errors of the mean values are represented by vertical bars.

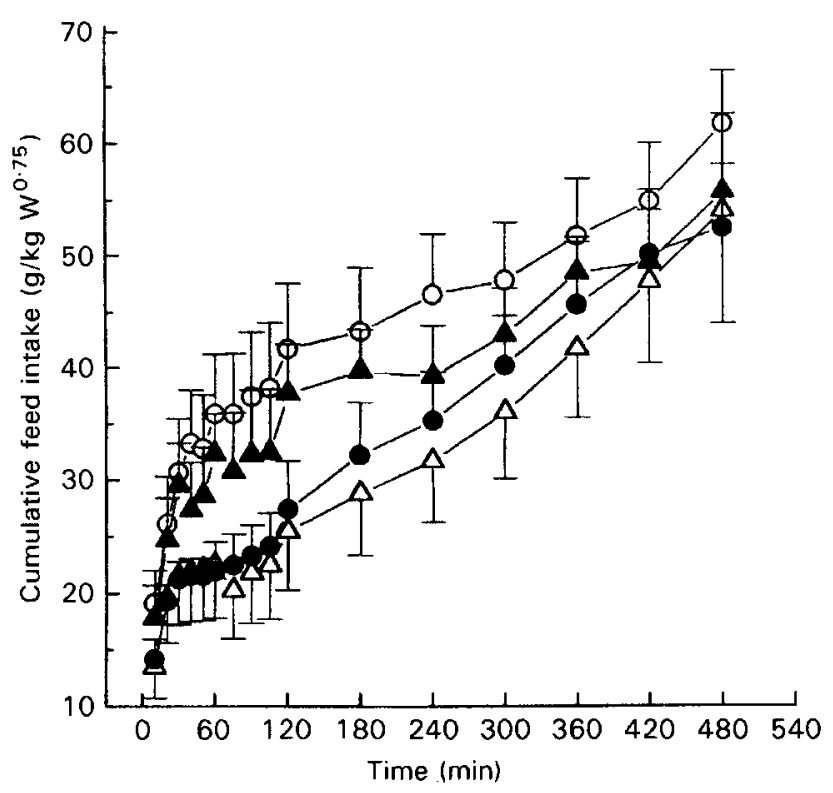

Fig. 5. Mean cumulative feed intake $\left(\mathrm{g} / \mathrm{kg}\right.$ body weight $\left.{ }^{0.75}\right)$ of noninfected lambs $(n 6)$ fed once daily and infused with saline solution (๑), cholecystokinin octapeptide (CCK-8) (2.5 pmol/min; $\triangle$ ), CCK antagonist $(162 \mu \mathrm{g} / \mathrm{min} ; \mathrm{O})$ or CCK-8 plus antagonist $(\Lambda)$ into a lateral ventricle of the brain for $30 \mathrm{~min}$ before feeding and for the first hour after feeding. Standard errors of the mean values are represented by vertical bars.

brain (Figs. 5 and 6). Loxiglumide increased intake gradually, with the increase becoming apparent at $30 \mathrm{~min}$ $(P<0.1)$ and being significant $(0.05>P>0.001)$ from

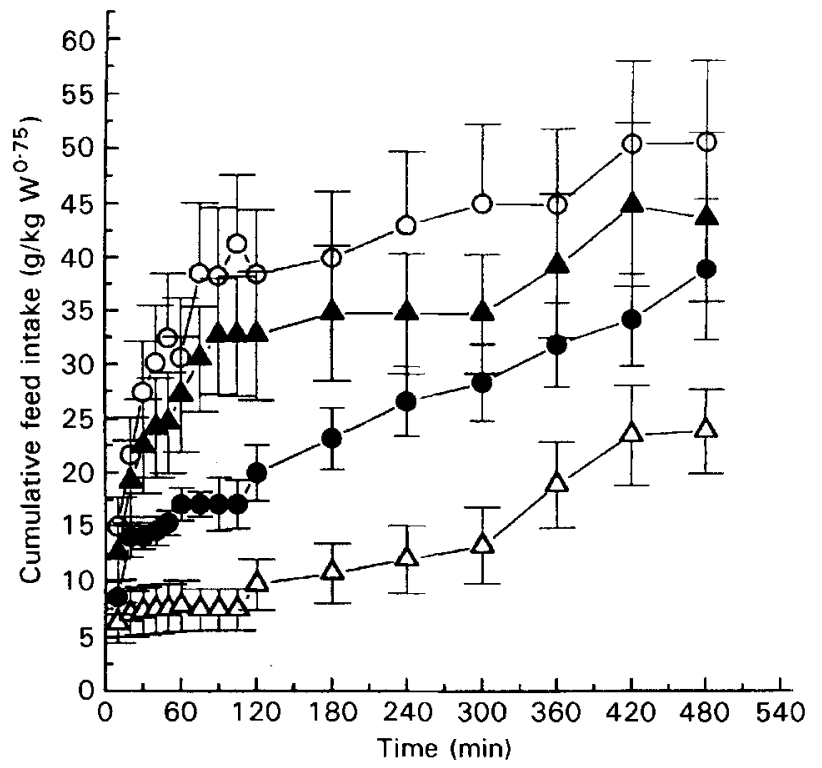

Fig. 6. Mean cumulative feed intake $\left(\mathrm{g} / \mathrm{kg}\right.$ body weight ${ }^{0.75}$ ) of lambs (n 6) infected with the parasite Trichostrongylus colubriformis fed once daily and infused with saline solution (0), cholecystokinin octapeptide (CCK-8, $2.5 \mathrm{pmol} / \mathrm{min}, \triangle$ ), CCK antagonist $(162 \mu \mathrm{g} / \mathrm{min}$, $0)$ or CCK-8 plus antagonist $(\boldsymbol{\Delta})$ into a lateral ventricle of the brain for $30 \mathrm{~min}$ before feeding and for the first hour after feeding. Standard errors of the mean values are represented by vertical bars.

$40 \mathrm{~min}$ through to $4 \mathrm{~h}$ in the non-infected animals and until the end of short-term recording $(7 \mathrm{~h})$ in infected animals.

Following the combined infusion of CCK-8 and loxiglumide into the lateral ventricle, feed intake was intermediate between that of the control (saline) and the loxiglumide alone (Figs. 5 and 6 ). In the infected groups the increases in intake above those of saline treatment were significant $(P<0.05)$ from $1.75 \mathrm{~h}$ after feeding. In the noninfected groups cumulative intake of CCK- 8 plus loxiglumide infused animals was significantly increased $(P<0.05)$ above that of controls only between $40 \mathrm{~min}$ and $3 \mathrm{~h}$ after feeding.

Relative to controls loxiglumide infusion into the lateral ventricle of the brain increased the rate of eating by $75 \%$ in the infected animals and $67 \%$ in non-infected animals during the first hour of feeding. However the greatest effect was evident in the second hour of feeding when noninfected and infected animals ate $16 \%(P=0.085)$ and $188 \%(P=0.001)$ more feed, respectively, following loxiglumide infusion than in the same period following saline treatment. During the final period $(2-7 \mathrm{~h})$ the loxiglumide treatment effects were no longer apparent and both groups tended to eat less feed than their respective controls, being $36 \%$ and $13 \%$ less for the infected and noninfected groups respectively. As a result of the early stimulation of intake, the cumulative intake for infected animals treated with loxiglumide was still significantly higher than the control intake (34.1 (SE 4.3) v. 50.4 (SE 7.5), $P<0.05)$ at the end of the short term recording period (7 h).

Between 1 and $2 \mathrm{~h}$ after feeding there was a significant $(P<0.05)$ infection $\times$ treatment interaction due to the infected animals suffering significant intake depression 
Table 1. Abomasal volume $(\mathrm{ml})$ and outflow rate $(\mathrm{ml} / \mathrm{min})$ of marker from the abomasum of infected and non-infected lambs $(n$ ) following intravenous infusion of saline solution or the cholecystokinin receptor antagonist, loxiglumide ${ }^{*}$

(Mean values with their standard errors)

\begin{tabular}{|c|c|c|c|c|c|c|c|c|}
\hline & \multicolumn{4}{|c|}{ Infected } & \multicolumn{4}{|c|}{ Non-infected } \\
\hline & \multicolumn{2}{|c|}{ Saline } & \multicolumn{2}{|c|}{ Loxiglumide } & \multicolumn{2}{|c|}{ Saline } & \multicolumn{2}{|c|}{ Loxiglumide } \\
\hline & Mean & $\mathrm{SE}$ & Mean & SE & Mean & SE & Mean & SE \\
\hline $\begin{array}{l}\text { Volume }(\mathrm{ml}) \\
\text { Outflow }(\mathrm{ml} / \mathrm{min})\end{array}$ & $\begin{array}{l}67^{\mathrm{a}} \\
2 \cdot 2^{\mathrm{a}}\end{array}$ & $\begin{array}{c}11.3 \\
0.17\end{array}$ & $\begin{array}{c}80^{\mathrm{a}} \\
2 \cdot 5^{\mathrm{a}}\end{array}$ & $\begin{array}{c}18-5 \\
0.14\end{array}$ & $\begin{array}{l}162^{\mathrm{b}} \\
2 \cdot 8^{\mathrm{b}}\end{array}$ & $\begin{array}{c}24.2 \\
0.12\end{array}$ & $\begin{array}{r}167^{\mathrm{b}} \\
2.8^{\mathrm{b}}\end{array}$ & $\begin{array}{r}27.9 \\
0.14\end{array}$ \\
\hline
\end{tabular}

a,b Mean values within a row with unlike superscript letters were significantly different, $P<0.05$.

* For details of procedures, see pp. 48-49.

following CCK-8 infusion when no effect was evident in the non-infected animals. Also the infected animals had a greater response to the intake-stimulating effects of loxiglumide.

Good linear relationships of the natural $\log$ of the marker concentration $v$. time were obtained $\left(r^{2}>0.9\right)$ for the data sets used in the prediction of abomasal volume and flow. The data indicate differences in the state of the abomasum in terms of volume and fractional outflow rate at a particular time. This is likely to be a function of the pattern of feeding as well as any specific effect on abomasal motility by the parasite. Parasite-infected sheep had a mean abomasal volume $60 \%$ lower than that of noninfected animals (Table 1). Treatment with loxiglumide had no effect on abomasal volume or rate of outflow in either infected or non-infected groups.

There was no significant $(P>0.05)$ effect of any pharmacological agent on total daily feed intake. All the observed effects were confined to the initial $7 \mathrm{~h}$ of the feeding period, i.e. in the short term.

\section{Discussion}

These experiments have illustrated the nature of postfasting feed intake in sheep with reduced daily intakes resulting from subclinical infection by $T$. colubriformis and they show that the intake depression can be reversed by administration of anthelmintics. More importantly, the finding that intracerebroventricular infusion of a CCK antagonist (loxiglumide) elevated feed intake in infected sheep supports the hypothesis that CCK is involved in appetite suppression of sheep with gastrointestinal parasitism. Furthermore it extends this hypothesis by linking the mechanism to central (brain) CCK receptors.

In the present study, although gastrointestinal parasitism caused a depression of daily feed intake typical for $T$. colubriformis (Steel et al. 1980; Dynes et al. 1990, 1991), the changes in short term intake recorded here demonstrate for the first time that depression in daily intake results from a reduction in the rate of feed intake by infected animals, rather than from an effect on pattern of eating.

The depression in daily intake and in the rate of eating was reversible. The rate of intake in the pre-infection period was similar in infected and non-infected animals, the parasitized group had a lower intake from about week 6 of infection and on administration of an anthelmintic their intake returned to the level of the non-infected group. This demonstrated that feed intake depression under parasitism can be examined by the cumulative intake model, making this a suitable tool for screening potentially therapeutic drugs. The differences were readily apparent in the first hour of feeding and in all subsequent periods recorded. Removal of the parasite reversed the short-term and daily intake depression, demonstrating that the presence of the parasite was instrumental in the feed intake depression.

A link between changes in circulating gut hormones and intake depression mediated by parasite infection was first suggested by Symons \& Hennessy (1981). The authors reported elevated circulating CCK levels during intake depression due to parasite infection. Intake depression due to a gut satiety hormone may be expected to change meal duration as reported for laboratory animals (Moran \& McHugh, 1988). Such an effect was not observed in this study although the tendency of infected animals to 'appear' to be eating would have required a load cell attached to each feed bin to detect accurately these differences.

A single dose of L364-718, increasing doses of loxiglumide or continuous infusion of loxiglumide failed to change short term feed intake in infected animals following systemic administration of these CCK antagonists. This finding provides initial evidence to discount a role for the elevation of peripheral CCK concentration being the primary disturbance to feed intake in infected lambs, either directly or indirectly via CCK effects on gut emptying.

Gastrointestinal parasite infections have been reported to alter gut motility and increase abomasal volume (Gregory et al. $1985 b$ ), but in the present study abomasal volume was reduced by $60 \%$ in infected animals. This discrepancy can be accounted for by the differences in voluntary feed consumption between the two studies. Abomasal volumes, even in the non-infected animals, were much lower than those reported by Gregory et al. $(1985 a, b)(162 \mathrm{ml} v .300-$ $900 \mathrm{ml}$ ) and this is probably largely due to differences in feeding regimens between the two experiments. In the present study, to facilitate testing of pharmacological agents, sheep were fed once daily, whereas Gregory et al. (1985a) used a continuous feeding regimen which produced steady-state rumen conditions and differences in the pattern of digesta flow from the gut compared with once daily feeding. The nature of the outflow from the abomasum could be quite different in the two circumstances, so it is 
not possible to compare the parasite-induced effects on abomasal volume and emptying reported by Gregory et al. $(1985 b)$ with the present findings.

We could not validate the use of loxiglumide or L364718 to block the action of peripheral CCK in sheep because we were unable to depress intake reliably with peripheral CCK administration. However, the response of the intakedepressed infected animals in this study was of particular interest. If, as Symons \& Hennessy (1981) suggested, elevated peripheral CCK levels were depressing feed intake, then loxiglumide should have blocked these effects at least in the short term. Instead there was no change in feed intake of infected animals with a range of doses or continuous infusion of loxiglumide, even at dose rates double those which are used orally in human subjects to completely inhibit gall bladder contractions (Corazziari $e t$ al. 1990). This tends to rule out a role for peripheral CCK in parasite-induced feed intake depression of sheep.

The effects of parasites on intake could be temporarily reversed. Loxiglumide elevated intake when infused directly into a lateral cerebral ventricle and this is the first evidence of a CCK receptor antagonist alleviating parasiteinduced intake depression in lambs. This finding supports the view that central mechanisms have an important role in feed intake depression and specifically implicates centrally secreted CCK. Similar evidence has been obtained from studies with pigs (Parrott, 1993; Rayner \& Miller, 1993; Baldwin et al. 1994). Loxiglumide is a pentanoic acid derivative which was originally developed as a therapeutic aid to manage CCK-dependent disorders in human subjects. Although loxiglumide has almost thirty times greater affinity for peripheral CCK than for central CCK receptors, its affinity for central receptors is still 19000 times greater than that of proglumide, the original CCK antagonist (Setnikar et al. 1987a). Studies on laboratory animals have demonstrated the antagonistic potency of loxiglumide on CCK-8-induced stimulation of gastrointestinal tissue (Setnikar et al. 1987b). However, there are no published studies of its effects on feed intake in sheep, so direct comparisons with the present findings are not possible. Nevertheless, other CCK antagonists have been utilized successfully to increase feed intake in animals, for example CR 1409 in rats (Makovec et al. 1986) and MK-329 (Rayner \& Miller, 1993) or 2-NAP (Baldwin et al. 1994) in pigs.

Loxiglumide infused into the lateral cerebral ventricle increased intake by changing the eating pattern in the first $2 \mathrm{~h}$ of feeding. The rate of feed consumption was elevated in both the first and second hours of feeding, but the most marked change occurred in the second hour when the rate of consumption was elevated by $188 \%$ in infected animals and by $16 \%$ in the non-infected group. Generally the second hour of feeding was observed to be a rest and/or rumination period in the usual eating pattern, but loxiglumide prolonged the meal, resulting in an almost continuous eating period, contrasting with the control treatments where animals stopped eating 40-60 min after feeding but had a second small meal between 1.25 and $2 \mathrm{~h}$ after feeding. Usually feeding was rapid for the first $20 \mathrm{~min}$ then declined to meal termination $40-50 \mathrm{~min}$ after feeding was initiated. Blockade of this effect by infusion of the
CCK receptor antagonist led to a prolonged first meal in both the infected and non-infected animals. Although there was a significant elevation of feed intake in the short term, this was not manifested as changes to daily intake in either group, possibly due to other constraints on intake, such as reticulo-rumen fill which may have reduced intake later in the day.

Intracerebroventricular infusion of the CCK octapeptide was very effective in reducing feed intake in the infected animals only, with the depression resulting in a much smaller than usual first meal followed by an extended intermeal interval, lasting between 2 and $3 \mathrm{~h}$ after feeding. Interestingly Della-Fera \& Baile (1979), also using a $2 \mathrm{~h}$ feed deprivation and $2.5 \mathrm{pmol} / \mathrm{min}$ intracerebroventricular infusion of CCK-8, found that healthy animals ate no feed at all for the duration of the $3 \mathrm{~h}$ infusion and as little as $0.159 \mathrm{pmol} / \mathrm{min}$ CCK depressed intake by $85 \%$ during the infusion period. In the present study there was no effect of CCK at all in non-infected animals and where it was effective in the infected animals the maximum recorded depression was only $52 \%$. Similarly, Farningham et al. (1993) recorded no effect of CCK-8 on feed intake in healthy sheep when it was administered alone, by hepatic portal infusion.

Conditioning to once daily feeding, as used in the present study, may lead to animals not eating for approximately $3 \mathrm{~h}$ before feed being offered then having a large meal of fresh feed (Forbes, 1980). Cumulative intake data recorded in the present study clearly depict the large initial meal the sheep ate immediately following provision of feed, so these animals may have had a greater hunger drive than would have been expected from a $2 \mathrm{~h}$ fast. However, CCK-8 depressed feed intake by $53 \%$ in $8 \mathrm{~h}$ fasted animals during a $3 \mathrm{~h}$ infusion (Della-Fera \& Baile, 1979), so it is surprising that a depression in feed intake in the non-infected animals of the present study was not seen during the $90 \mathrm{~min}$ infusion.

Differing responsiveness to CCK-8 infusion between infected and non-infected animals may be due to the infected animals having higher levels of endogenous brain and/or central CCK activity acting directly on satiety centres, with the result that the addition of exogenous CCK was sufficient to precipitate a satiety signal and reduce intake accordingly. In the non-infected animals endogenous central CCK levels or activity may have been low (Scallett et al. 1985) and, despite the infusion, were insufficient to elicit satiety effects.

Intracerebroventricular administration of loxiglumide not only increased the rate of consumption of feed but also appeared to increase the duration of the first meal. The response was greater in infected animals but the stimulation occurred in both groups and suggests an involvement of central CCK in feed intake regulation of sheep in general, rather than a role specific to the parasite-induced disturbance.

\section{Acknowledgements}

R.A.D. was supported financially by a New Zealand University Grants Committee postgraduate scholarship and by 
Lincoln University Research Council during this work. We acknowledge the generous support of Dr G.S.G. Spencer and advice of Dr L. Rovatti. The surgical skills of Dr A. S. Familton and the technical support of Mr R. McAnulty, Ms J. Nahkies and Mr J. Morgan are acknowledged. Statistical advice and assistance by Dr B. Robson is acknowledged. Loxiglumide was a gift from the Rotta Research Laboratorium, Italy and L364-718 was donated by Merck, Sharpe and Dohme, UK.

\section{References}

Baldwin BA, de la Riva C \& Gerskowitch VP (1994) Effect of a novel CCK-A receptor antagonist (2-NAP) on the reduction in food intake produced by $\mathrm{CCK}$ in pigs. Physiology and Behavior 55, 175-179.

Chang RSL \& Lotti VJ (1986) Biochemical and pharmacological characterisation of an extremely potent and selective nonpeptide cholecystokinin antagonist. Proceedings of the National Academy of Sciences USA 83, 4923-4926.

Corrazziari E, Ricci R, Biliotti D, Bontempi I, De Medici A, Pallotta N \& Torsoli A (1990) Oral administration of loxiglumide $\mathrm{CCK}$ antagonist inhibits postprandial gall bladder contraction without affecting gastric emptying. Digestive Diseases and Sciences 35, 50-54.

Della-Fera MA \& Baile CA (1979) Cholecystokinin octapeptide: continuous picomole injections into the cerebral ventricles suppress feeding. Science 206, 471-473.

Della-Fera MA \& Baile CA (1981) Cholecystokinin antibody injected into cerebral ventricles stimulated feeding in sheep. Science 212, 687-689.

Dynes RA, Ankersmit AEL, Poppi DP, Sykes AR \& Barrell GK (1990) Studies on the physiological basis of appetite depression in nematode infection in sheep. Proceedings of the New Zealand Society of Animal Production 50, 249-254.

Dynes RA, Poppi DP, Barrell GK \& Sykes AR (1991) Effects of fasting and an opioid antagonist on feed intake in lambs injected with intestinal parasites. Proceedings of the New Zealand Society of Animal Production 51, 371-374.

Faichney GJ (1975) The use of markers to partition digestion within the gastro-intestinal tract of ruminants. In Digestion and Metabolism in the Ruminant, pp. 277-291 [IW McDonald and ACI Warner, editors]. Armidale, NSW: University of New England Publishing Unit.

Farningham DAH, Mercer JG \& Lawrence CB (1993) Satiety signals in sheep: involvement of $\mathrm{CCK}$, propionate, and vagal CCK binding sites. Physiology and Behavior 54, 437-442.

Forbes JM (1980) A model of the short-term control of feeding. Appetite 1, 21-41.

Gregory PC, Miller SJ \& Brewer AC (1985a) The relation between food intake and abomasal emptying and small intestinal transit time in sheep. British Journal of Nutrition 53, 373-380.
Gregory PC, Wenham G, Poppi DP, Coop RL, MacRae JC \& Miller SJ (1985b) The influence of a chronic subclinical infection of Trichostrongylus colubriformis on gastrointestinal motility and digesta flow in sheep. Parasitology 91, 381-386.

Hecker JF (1974) Experimental Surgery on Small Ruminants. London: Butterworths.

Hoebel BG (1985) Integrative peptides. Brain Research Bulletin 14, 525-528.

Makovec F, Bani M, Cereda R, Chiste R, Revel L, Rovati LC, Setnikar I \& Rovati LA (1986) Protective effect of CR 1409 on experimental pancreatitis in rats and mice. Peptides 7, 11591164.

Marson I, Lauterio TL, Baile CA \& Della-Fera MA (1986) Comparative distribution of cholecystokinin, met-enkephalin and dynorphin A in sheep and rats hypothalamus. Society of Neuroscience Abstracts 12, 297.

Ministry of Agriculture, Fisheries and Food (1979) Manual of Veterinary Parasitology Techniques. Technical Bulletin no. 18, London: H.M. Stationery Office.

Moran TH \& McHugh PR (1988) Gastric and nongastric mechanisms for satiety action of cholecystokinin. American Journal of Physiology 254, R628-R632.

Morley JE, Levin AS \& Knelp J (1981) Muscimol induced feeding: a model to study the hypothalamic regulation of appetite. Life Science 29, 1213-1218.

Parrott RF (1993) Peripheral and central effects of CCK receptor agonists on operant feeding in pigs. Physiology and Behavior 53, 367-372.

Poppi DP, Sykes AR \& Dynes RA (1990) The effect of endoparasitism on host nutrition - the implications for nutrient manipulation. Proceedings of the New Zealand Society of Animal Production 50, 237-244.

Rayner DV \& Miller S (1993) Voluntary intake and gastric emptying in pigs: effects of fat and a CCK inhibitor. Physiology and Behavior 54, 917-922.

Scallett AC, Della-Fera MA \& Baile CA (1985) Satiety, hunger and regional brain content of cholecystokinin and metenkephalin in sheep. Peptides 6, 937.

Setnikar I, Bani M, Cereda R, Chiste R, Makovec F, Palini MA \& Revel L (1987a) Loxiglumide protects against experimental pancreatitis. Drug Research 37(II), 1172-1174.

Setnikar I, Bani M, Cereda R, Chiste R, Makovec F, Palini MA, Revel L, Rovati LC \& Rovati LA (1987b) Pharmacological characterisation of a new potent and specific nonpolypeptidic cholecystokinin antagonist. Drug Research 37(I), 703-707.

Steel JW, Symons LEA \& Jones WO (1980) Effects of level of larval intake on the productivity and physiology and metabolic responses of lambs infected with Trichostrongylus colubriformis. Australian Journal of Agricultural Research 31, 821828.

Symons LEA \& Hennessy DR (1981) Cholecystokinin and anorexia in sheep infected by the intestinal nematode. Trichostrongylus colubriformis. International Journal of Parasitology 11, 55-58. 